\title{
Melatonin confers drought stress tolerance in soybean (Glycine max L.) by modulating photosynthesis, osmolytes, and reactive oxygen metabolism
}

\author{
L. CAO ${ }^{\dagger}$, X.J. JIN ${ }^{\dagger}$, and Y.X. ZHANG ${ }^{+}$ \\ Heilongjiang Bayi Agricultural University, Daqing, 163000 Heilongjiang, China
}

\begin{abstract}
In order to investigate the role of melatonin in the drought tolerance, we examined pigments, gas exchange, osmolytes, and reactive oxygen radical metabolism in soybean plants. Drought declined photosynthetic pigments and caused irreversible reduction in net photosynthesis, which was followed by stomatal limitation for 5 and $10 \mathrm{~d}$ and nonstomatal limitation for $15 \mathrm{~d}$. Soluble sugar, soluble proteins, and proline concentrations were higher in drought-stressed seedlings compared with the control. The contents of superoxide anion, hydrogen peroxide, and malondialdehyde increased during drought stress indicating oxidative stress. Drought stress also increased superoxide dismutase, peroxidase, and catalase activities. Melatonin treatment improved the tolerance of drought-treated plants, which was possibly due to the enhanced content of osmolytes and higher antioxidant enzyme activities that retard dehydration and lipid peroxidation.
\end{abstract}

Additional key words: carotenoid; chlorophyll; gas-exchange parameters; plant growth regulator; reactive oxygen species.

\section{Introduction}

Drought is an abiotic stress that has drastic effect on the growth and development of plants, especially at the seedling stage, which affects the global grain production (Du et al. 2004, Basu et al. 2010, Deng et al. 2012, Hu et al. 2013, Kaczmarek et al. 2017). In spring, drought can kill seedlings through their root systems, which are not fully developed (Kaczmarek et al. 2017). With the rising global temperature, the timing and magnitude of drought stress has been increasing yearly, especially, in arid and semiarid regions (Wang et al. 2013, Harrison et al. 2014).

Many studies have reported that when plants encounter a water deficit, there is a disturbance in water balance, and a decline in photosynthesis (Fu and Huang 2001, Hu et al. 2013, Cui et al. 2017). Kaczmarek et al. (2017) proposed that osmolyte accumulation was the first line of defense against drought. The most common compatible osmolytes, such as soluble sugars, soluble proteins, and proline, can reduce membrane permeability, and play an important role in maintaining water balance in plants under mild water stress (Du et al. 2004). Through stomatal and nonstomatal limitations, drought stress inhibits photosynthesis and is usually accompanied by a decline in light energy absorption. Stomatal closure leads to a leakage of electrons towards $\mathrm{O}_{2}$, resulting in increased reactive oxygen species (ROS) generation in water-deficient plants (Basu et al. 2010). Superoxide $\left(\mathrm{O}_{2}{ }^{-}\right)$and hydrogen peroxide $\left(\mathrm{H}_{2} \mathrm{O}_{2}\right)$, which are the major ROS, accumulate in cells and cause oxidative stress (Basu et al. 2010, Deng et al. 2012). These ROS can disrupt normal metabolism during stress, leading to membrane lipid peroxidation, chlorophyll (Chl) loss, and enzyme inactivation, which can accelerate plant senescence. Superoxide dismutase (SOD), peroxidase (POD), and catalase (CAT) are antioxidant enzymes that play key roles in eliminating excessive ROS in cell, and maintain ROS homeostasis and tolerance to stress, including drought stress (Basu et al. 2010, Deng et al. 2012).

Melatonin ( $N$-acetyl-5-methoxytryptamine) is a steroidal tryptamine that is a well-known hormone in plants and animals. In 1995, melatonin was discovered in higher plants, and it is a plant growth regulator (PGR) that is widely used to regulate growth and enhance plant resistance (Dubbels et al. 1995, Hattori et al. 1995). In a normal growth environment, melatonin has been shown to be a ubiquitous modulator of developmental processes, such as the preservation of $\mathrm{Chl}$, promotion of photosynthesis (Tan et al. 2012), and regeneration of root system architecture (Zhang et al. 2014). In addition, melatonin is an effective

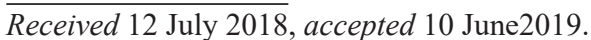

${ }^{+}$Corresponding author; e-mail: zyx 1xy@,126.com

Abbreviations: $\mathrm{Car}$ - carotenoid; $\mathrm{CAT}$ - catalase; $\mathrm{Chl}$ - chlorophyll; $C_{\mathrm{i}}$ - intercellular $\mathrm{CO}_{2}$ concentration; $\mathrm{DAB}$ - 3,3-diaminobenzidine; $E$ - transpiration rate; FM - fresh mass; $g_{\mathrm{s}}$ - stomatal conductance; MDA - malondialdehyde; NBT - nitroblue tetrazolium chloride; PGR - plant growth regulator; $P_{\mathrm{N}}$ - net photosynthetic rate; POD - peroxidase; ROS - reactive oxygen species; RSWC - relative soil water content; SOD - superoxide dismutase; VC - cotyledon stage; V1 - the second trifoliate leaf stage.

Acknowledgements: This study was funded by the National Natural Science Foundation (No. 31401332, No. 31371560), the China Agriculture Research System (CARS-04-01A), Natural Science Foundation of Heilongjiang Province of China (C2017049), The National Key Technology R\&D Program (2014BAD11B01-02), Key Project of Crop Science in Heilongjiang Bayi Agricultural University of China (ZWXQDJ-4), the project of the General Administration of Agriculture and Reclamation in Heilongjiang Province of China (HNK135-02-06).

These authors have contributed equally to this work. 
free radical scavenger and antioxidant in plants (Tan et al. 2012) that protects against multiple abiotic stresses, such as salt stress (Li et al. 2012), heavy metal stress (Posmyk et al. 2008), and UV radiation (Zhang et al. 2012). Previous studies have shown that melatonin can increase the germination rate and promote root growth in cucumber (Zhang et al. 2012), and delay drought-induced senescence in apple leaves (Wang et al. 2013). Although there are many studies on the effects of melatonin on drought stress, the results have significant limitations: (1) the research subjects are mainly horticultural crops (such as cucumbers, apples, etc.), and there are few studies on field crops; and (2) polyethylene glycol (PEG) was used to simulate drought, which cannot truly reflect the natural process of drought (Basu et al. 2010, Deng et al. 2012). The mechanisms underlying the effect of melatonin on soybean drought tolerance are unknown. Therefore, in this study, using cv. Suinong 26 as the test material, we simulated natural drought and normal water treatment at the seedling stage. We administered melatonin by spraying in order to test the effects of melatonin on the growth, photosynthesis, and antioxidant system of soybean seedlings under drought stress, which could provide a theoretical basis for the cultivation of drought-resistant soybeans.

\section{Materials and methods}

Experimental site and design: The experimental site was chosen at Heilongjiang Bayi Agricultural University located in Northeast China $\left(124^{\circ} 19^{\prime}-125^{\circ} 12^{\prime} \mathrm{E}, 45^{\circ} 46^{\prime}-\right.$ $\left.46^{\circ} 55^{\prime} \mathrm{N}\right)$ in 2018 . The soybean (Glycine $\max$ L.), variety Suinong 26, was sown at a rate of eight seeds per plastic pot $(33 \times 30 \mathrm{~cm})$ in a mixture of vermiculite and perlite in a $1: 1(\mathrm{v} / \mathrm{v})$ ratio and watered with full strength Hoagland solution once per day from sowing to emergence, and twice per day after emergence. In order to prevent excessive accumulation of salt in the mixed perlite and vermiculite, the pots were watered with distilled water once every $5 \mathrm{~d}$. Three seedlings were retained at the cotyledon stage (VC).

The melatonin (Sigma, St. Louis, MO, USA) and drought treatments were applied at the second trifoliate leaf stage (V1). Before the treatments were applied, the pots were divided into two groups, drought-stressed and wellwatered. Drought-stressed pots were kept at $45 \%$ relative soil water content (RSWC), and well-watered pots were watered up to $80 \%$ RSWC (Hu et al. 2013). Half of the pots were sprayed with $45 \mathrm{~mL}$ of a $100 \mathrm{mg} \mathrm{L}^{-1}$ melatonin solution (Wang et al. 2013) for $3 \mathrm{~d}$ before the drought treatment. The rest were sprayed with distilled water as a control treatment. Each pot was weighed daily for $15 \mathrm{~d}$ to maintain the soil moisture levels at 45 or $80 \%$ by adding lost water. There were four treatments: (1) control (CK): well-watered $(80 \%)$ and sprayed with distilled water; (2) $\mathrm{CK}+\mathrm{M}$ : well-watered $(80 \%)$ and sprayed with melatonin; (3) drought (D): drought-stressed (45\%) and sprayed with distilled water; (4) D + M: drought-stressed (45\%) and sprayed with melatonin. The experimental design was a randomized complete design with four replications. Fully expanded leaves (i.e., second trifoliate leaves from the main apex) were sampled from each treatment at three time points $(5,10$, and $15 \mathrm{~d})$ after exposure to drought treatments, and frozen in liquid nitrogen, and stored at $-80^{\circ} \mathrm{C}$.

Photosynthetic pigments concentrations: $\mathrm{Chl} a, \mathrm{Chl} b$, Chl $(a+b)$, and carotenoid (Car) concentrations were determined according to the method of Arnon (1949) with a minor modification. Fresh leaf tissue from fully expanded healthy leaves $(100 \mathrm{mg})$ was soaked in $10 \mathrm{~mL}$ of ethanol absolute for $24 \mathrm{~h}$ until the pellets became colorless. The optical density (D) of the solution was measured at 470 , 649, and $665 \mathrm{~nm}$, using a UV-visible spectrophotometer (Jenway 6850 UV-Vis, Cole-Parmer Ltd., UK). Contents were calculated as follows:

Chl $a=13.95 \mathrm{D}_{665}-6.88 \mathrm{D}_{649}$

Chl $b=24.96 \mathrm{D}_{649}-7.32 \mathrm{D}_{665}$

$\mathrm{Car}=\left(1000 \mathrm{D}_{470}-2.05 \mathrm{Chl} a-111.48 \mathrm{Chl} b\right) / 245$

Gas-exchange parameters: The net $\mathrm{CO}_{2}$ assimilation rate $\left(P_{\mathrm{N}}\right)$, stomatal conductance $\left(g_{\mathrm{s}}\right)$, transpiration rate $(E)$, and intercellular $\mathrm{CO}_{2}$ concentration $\left(C_{\mathrm{i}}\right)$ were measured in the youngest and fully expanded leaves using a portable photosynthesis system ( $\mathrm{Li}$-Cor 6400, Li-Cor Inc., Nebraska, USA) under the following conditions: light intensity of $1,000 \mu \mathrm{mol}$ (photon) $\mathrm{m}^{-2} \mathrm{~s}^{-1}, \mathrm{CO}_{2}$ concentration of $380 \mu \mathrm{mol} \mathrm{mol}^{-1}$, flow rate of $500 \mu \mathrm{mol} \mathrm{s}^{-1}$, leaf temperature of $27 \pm 2^{\circ} \mathrm{C}$, and relative humidity of $65 \pm 5 \%$. Measurements were taken from 9:30 to 11:30 h.

Osmolyte concentrations: Soluble sugars were extracted according to the method of Hendrix (1993) with slight modifications. Frozen leaf samples (about $1.0 \mathrm{~g}$ of fresh mass) were grounded in liquid nitrogen, extracted in $7.0 \mathrm{~mL}$ of $80 \%(\mathrm{v} / \mathrm{v})$ ethanol three times, immersed in a $80^{\circ} \mathrm{C}$ water bath for $15 \mathrm{~min}$, and centrifuged at $6,000 \times g$ for $5 \mathrm{~min}$. After centrifugation, the supernatant was recovered and brought to a volume of $25 \mathrm{~mL}$. Then $0.5 \mathrm{~mL}$ of the supernatant was mixed with $2.0 \mathrm{~mL}$ of distilled water and $6.5 \mathrm{~mL}$ of anthrone solution. The absorbance of the supernatant was read at $620 \mathrm{~nm}$ using a UV-Vis spectrophotometer (Jenway $6850 \mathrm{UV}$-Vis, ColeParmer Ltd., UK).

The soluble protein concentration was estimated spectrophotometrically according to the method of Smith et al. (1985). Freshly harvested leaf samples (1.0 g fresh mass) were homogenized with $0.1 \mathrm{M}$ phosphate buffer $(\mathrm{pH}$ 6.75). Then, the homogenates were centrifuged at $15,000 \times g$ for $15 \mathrm{~min}$. Next, $5 \mu \mathrm{L}$ of supernatant was transferred to tubes and mixed with $1.5 \mathrm{~mL}$ of BCA reagent (bicionchonic acid $+\mathrm{FeCl}_{3}$ ). The samples were incubated in boiling water for $5 \mathrm{~min}$ and then cooled to room temperature. The absorbance at $562 \mathrm{~nm}$ was measured with a spectrophotometer (Jenway $6850 \mathrm{UV}$-Vis, Cole-Parmer Ltd., UK) and the concentration of soluble protein was expressed as $\mathrm{mg} \mathrm{g}^{-1}$.

The proline concentration was assayed according to the method of Bates et al. (1973) with slight modifications. Approximately $0.5 \mathrm{~g}$ of leaf sample was boiled in $3 \% 5$-sulfosalicylic acid and then centrifuged at 11,500 $\times g$ 
for $12 \mathrm{~min}$. Then, $2.0 \mathrm{~mL}$ of the supernatant was mixed with $2.0 \mathrm{~mL}$ of glacial acetic acid and $2.0 \mathrm{~mL}$ of acidninhydrin, boiled for $30 \mathrm{~min}$, and then cooled to room temperature. The developed color was extracted with $5 \mathrm{~mL}$ of toluene, and the absorbance was read at $520 \mathrm{~nm}$ using a UV-Vis spectrophotometer (Jenway $6850 \mathrm{UV}$-Vis, ColeParmer Ltd., UK).

Histochemical localization of hydrogen peroxide and superoxide anion: Leaves were collected from the same position in the plants and were then stained with nitroblue tetrazolium chloride (NBT) and 3,3-diaminobenzidine (DAB) solution according to the method of Chen et al. (2010) and Wei et al. (2015), respectively. The reaction of DAB with $\mathrm{H}_{2} \mathrm{O}_{2}$ produced brown spots, and the reaction of NBT with $\mathrm{O}_{2}^{-}$produced dark blue spots. All the leaves from the different treatments were incubated for $6 \mathrm{~h}$ and were immersed in a boiling mixed solution (ethanol:glacial acetic acid, 3:1, v/v) to visualize the spots.

Measurement of superoxide anion, hydrogen peroxide, and lipid peroxidation: The superoxide anion $\left(\mathrm{O}_{2}{ }^{-}\right)$ production rate was determined as previously described (Wang and Luo 1990). Briefly, leaf samples (0.2 g) were homogenized in $5 \mathrm{~mL}$ of ice cold $50 \mathrm{mM}$ phosphate buffer $(\mathrm{pH} \mathrm{7.8)}$ and then centrifuged at $16,000 \times g$ for $20 \mathrm{~min}$ at $4^{\circ} \mathrm{C}$. The supernatant was mixed with $1.0 \mathrm{~mL}$ of hydroxylamine hydrochloride and $2.0 \mathrm{~mL}$ of extraction buffer, and incubated for $20 \mathrm{~min}$. The production rate of $\mathrm{O}_{2}{ }^{-}$was measured spectrophotometrically at $530 \mathrm{~nm}$ (UV-3600 Plus, Shimadzu, Japan) and expressed as mmol $\min ^{-1} \mathrm{~g}^{-1}$ (protein).

The $\mathrm{H}_{2} \mathrm{O}_{2}$ concentration was determined by the method of Patterson et al. (1984). Firstly, $0.1 \mathrm{~g}$ of leaf tissue was homogenized with $5 \mathrm{~mL}$ of ice-cold acetone and centrifuged at $3,000 \times g$ for $10 \mathrm{~min}$. Then, $1.0 \mathrm{~mL}$ of the supernatant was added to $0.1 \mathrm{~mL}$ of $5 \%$ titanium sulfate, and $0.2 \mathrm{~mL}$ of concentrated ammonia and centrifuged at $3,000 \times g$ for $10 \mathrm{~min}$ again. The residual tissue was washed with $5 \mathrm{~mL}$ of sulfuric acid. Absorbance was measured spectrophotometrically at $415 \mathrm{~nm}$. The $\mathrm{H}_{2} \mathrm{O}_{2}$ concentration was calculated using $\mathrm{H}_{2} \mathrm{O}_{2}$ as a standard and expressed as $\mu \mathrm{mol} \mathrm{g} \mathrm{g}^{-1}(\mathrm{FM})$.

Lipid peroxidation was determined based on the malondialdehyde (MDA) concentration according to the method of Guidi et al. (2000). Approximately $1.0 \mathrm{~g}$ of fresh leaves was homogenized in $5 \mathrm{~mL}$ of $0.05 \mathrm{M}$ phosphate buffer $(\mathrm{pH} 7.8)$ and was centrifuged at $12,000 \times g$ for $20 \mathrm{~min}$. The mixture contained $2 \mathrm{~mL}$ of the supernatant and $2 \mathrm{~mL}$ of $0.6 \%$ thiobarbituric acid in $10 \%$ trichloroacetic acid containing $0.25 \%$ thiobarbituric acid, which was incubated in water bath at $95^{\circ} \mathrm{C}$ for $30 \mathrm{~min}$, quickly cooled in an ice bath, and then centrifuged at $10,000 \times \mathrm{g}$ for $10 \mathrm{~min}$. The absorbance of the supernatant was determined at 450 , 532, and $600 \mathrm{~nm}$ (Jenway $6850 \mathrm{UV}$-Vis, Cole-Parmer Ltd.,

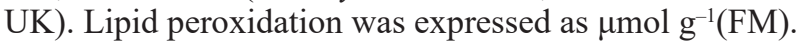

Antioxidant enzyme assays: Using a precooled mortar and pestle, soybean leaves $(0.5 \mathrm{~g})$ were homogenized in $10 \mathrm{~mL}$ of $50 \mathrm{mM}$ ice cold PBS buffer (pH 7.0) and then centrifuged at $11,500 \times g$ for $15 \mathrm{~min}$ at $4^{\circ} \mathrm{C}$. The supernatant was used for the enzyme activity assay.

Superoxide dismutase (SOD, EC 1.15.1.1.) was determined by measuring the ability to inhibit the photochemical reduction of nitroblue tetrazolium (NBT), according to the method of Alonso et al. (2001) with some modifications. The reaction mixture, which contained $2.4 \mathrm{~mL}$ of $50 \mathrm{mM}$ phosphate buffer ( $\mathrm{pH} 7.8$ ), $0.2 \mathrm{~mL}$ of $75 \mathrm{mM}$ NBT, $0.2 \mathrm{~mL}$ of $13 \mathrm{mM}$ methionine, $0.1 \mathrm{~mL}$ of $100 \mathrm{mM}$ EDTA, and $0.2 \mathrm{~mL}$ of $2 \mathrm{mM}$ riboflavin (added last) was added to tubes containing $0.2 \mathrm{~mL}$ of enzyme extract. These tubes were exposed to fluorescent tubes emitting a photon flux density of around $600 \mu \mathrm{mol} \mathrm{m} \mathrm{m}^{-2} \mathrm{~s}^{-1}$ for $10 \mathrm{~min}$ and then covered with a black cloth. The change in the absorbance at $560 \mathrm{~nm}$ was read with a UV-Vis spectrophotometer (Jenway 6850 UV-Vis, Cole-Parmer Ltd., UK). The unit of SOD activity was defined based on the standard curve and was expressed as $\mu \mathrm{mol} \mathrm{min} \mathrm{mg}^{-1}$ (protein).

Peroxidase (POD, EC 1.11.1.7.) activity in the leaves was measured according to the method of Maehly (1954) based on the increase in absorbance at $470 \mathrm{~nm}$. Peroxidase was assayed using guaiacol as the substrate. The assay solution for POD activity $(3.0 \mathrm{~mL})$ contained $0.3 \% \mathrm{H}_{2} \mathrm{O}_{2}$, $50 \mathrm{mM}$ phosphate buffer ( $\mathrm{pH} 7.0)$, and $0.2 \%$ guaiacol. The reaction was initiated by adding $0.2 \mathrm{~mL}$ of crude enzyme extract. The activity of POD was expressed as $\mu \mathrm{mol} \mathrm{min}^{-1}$ $\mathrm{mg}^{-1}$ (protein)

Catalase (CAT, EC 1.11.1.6.) activity was assayed according to the method of $\mathrm{Fu}$ and Huang (2001) by monitoring the disappearance of $\mathrm{H}_{2} \mathrm{O}_{2}$ as the decrease in the absorbance at $240 \mathrm{~nm}$ for $1 \mathrm{~min}$ (Jenway $6850 \mathrm{UV}$-Vis, Cole-Parmer Ltd., UK). The reaction mixture contained $1.5 \mathrm{~mL}$ of $50 \mathrm{mM}$ sodium phosphate buffer $(\mathrm{pH} 7.8)$, $0.1 \mathrm{~mL}$ of enzyme extract, and $0.3 \mathrm{~mL}$ of $1.5 \mathrm{M} \mathrm{H}_{2} \mathrm{O}_{2}$. The activity was calculated using the extinction coefficient of

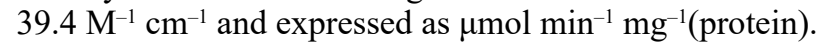

Statistical analysis: The data are presented as the means of four replicates. All data were subjected to analysis of variance (ANOVA) and Duncan's multiple range test. Differences between the treatments and control were considered significant at $P<0.05$, calculated by using $S P S S$ (21.0) software. Figures were drawn with OriginPro 9.1 software (OriginLab, Northampton, MA, USA).

\section{Results}

Photosynthetic pigments: Melatonin treatment increased the contents of $\mathrm{Chl}$ and Car under both well-watered and drought-stress conditions (Fig. 1). Drought stress significantly decreased the concentration of $\mathrm{Chl} a, \mathrm{Chl} b$, Chl $(a+b)$, and Car, from day 5 to day 15, these indicators decreased by $18.4-42.2,39.7-82.7,29.0-45.5$, and 49.1-60.9\%, respectively, when compared to well-watered plants. However, exogenous melatonin effectively relieved these decreases in drought-stressed plants. From day 5 to day 15 , the above indicators [Chl $a, \mathrm{Chl} b, \mathrm{Chl}(a+b)$, and Car] decreased by $7.5-25.3,18.1-42.2,12.8-33.8$, and $54.8-73.3 \%$, respectively. 


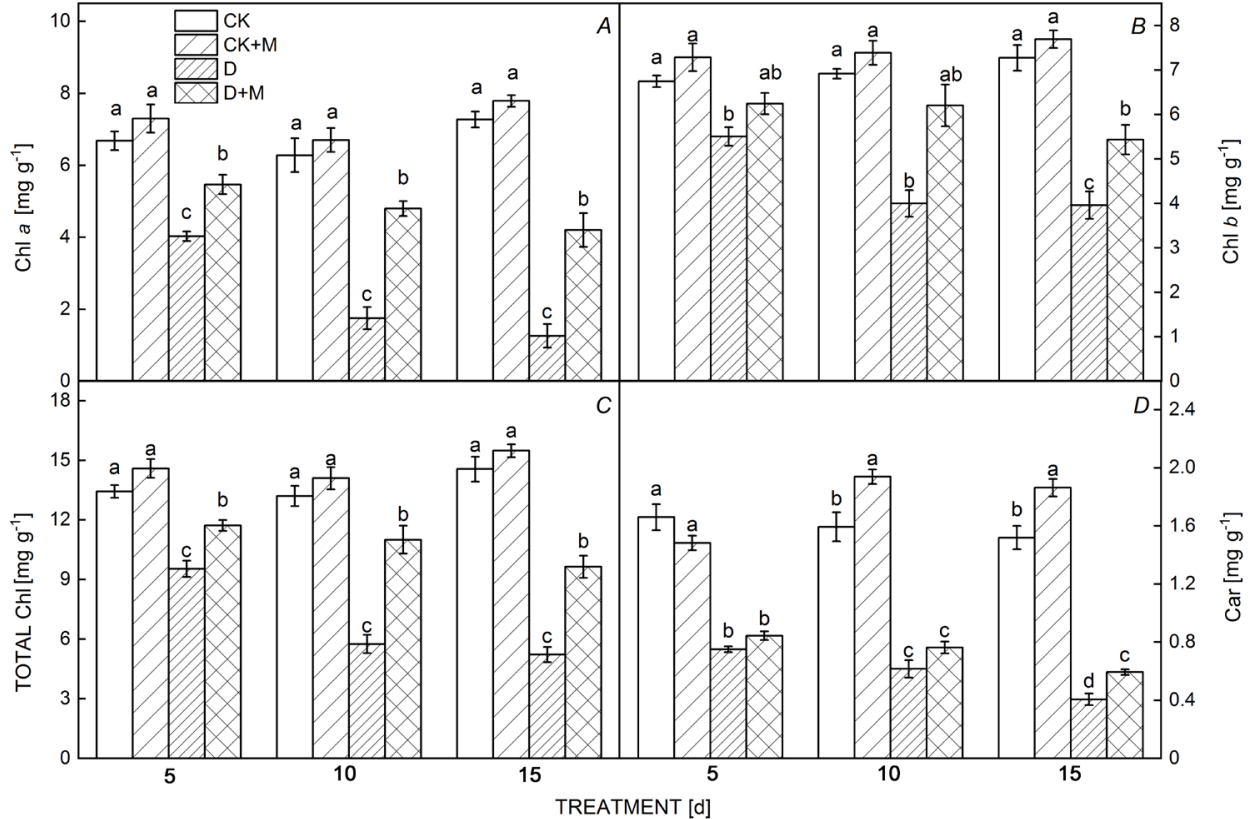

Fig. 1. Effect of melatonin on chlorophyll (Chl) $a(A), \mathrm{Chl} b(B)$, Chl $(a+b)(C)$, and carotenoid (Car) concentration $(D)$ in soybean leaves under wellwatered and drought stress conditions. All data are means $\pm \operatorname{SE}(n=4)$. Different letters above horizontal lines indicate significant differences $(P<0.05)$ between treatments. CK - wellwatered con-ditions, $\mathrm{CK}+\mathrm{M}$ - well-watered conditions + melatonin, D - drought stress, D $+\mathrm{M}-$ drought stress + melatonin.
Photosynthesis: As shown in Fig. 2, melatonin significantly increased $P_{\mathrm{N}}, g_{s}$, and $E$ under well-watered conditions. With prolonged treatment time, $P_{\mathrm{N}}$ increased from 5.9 to $13.4 \%$. Drought stress sharply decreased $P_{\mathrm{N}}$ and $g_{s}$. However, melatonin markedly alleviated the drought-induced reductions in $P_{\mathrm{N}}$ and $g_{s}$. Compared to well-watered plants, $P_{\mathrm{N}}$ was reduced by $31.5-67.2 \%$ in drought-stressed plants, and by $13.4-43.6 \%$ in melatonintreated drought-stressed plants.

Osmolyte concentration: Drought stress increased the concentrations of various osmolytes, such as soluble sugar, soluble protein (Fig. 3), and proline (Table 1), and compared to well-watered plants, the concentrations of soluble sugar after 5,10 , and $15 \mathrm{~d}$ of drought stress increased by 16.8 ,
49.9 , and $89.1 \%$, respectively. In contrast, melatoninpretreated drought-stressed soybean plants showed increases of $4.8,13.4$, and $15.3 \%$ after 5,10 , and $15 \mathrm{~d}$ of drought stress, respectively (Fig. $3 A$ ). Compared with wellwatered plants, the increases in soluble protein were 30.0, 53.6 , and $74.6 \%$ in drought-stressed plants, respectively. Compared to drought-stressed plants without melatonin, drought-stressed plants pretreated with melatonin showed 8.6, 15.0, and 19.2\% higher concentrations of soluble protein after 5,10 , and $15 \mathrm{~d}$ of drought stress, respectively (Fig. 3B). Without melatonin, a significant increase in the proline concentration was observed in drought-stressed plants over time as compared with the contents in wellwatered plants (Table 1). Soybean seedlings showed higher endogenous proline concentrations, which increased by

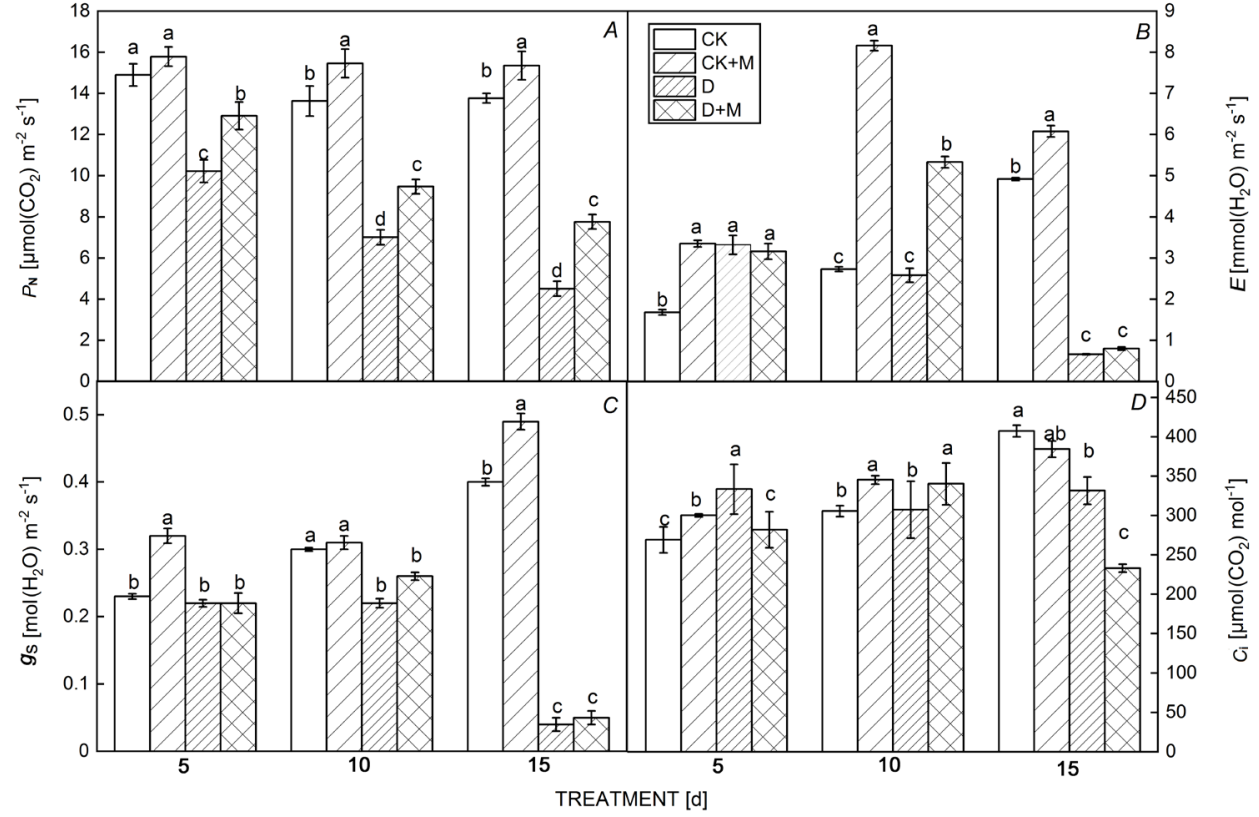

Fig. 2. Effect of melatonin on net photosynthetic rate $\left(P_{\mathrm{N}}\right)(A)$, transpiration rate $(E)(B)$, stomatal conductance $\left(g_{\mathrm{s}}\right)(C)$, and intercellular $\mathrm{CO}_{2}$ concentration $\left(C_{\mathrm{i}}\right)$ $(D)$ in soybean leaves under well-watered and drought stress conditions. All data are means \pm SE $(n=4)$. Different letters above horizontal lines indicate significant differences $(P<0.05)$ between treatments. CK - wellwatered conditions, $\mathrm{CK}+\mathrm{M}-$ well-watered conditions + melatonin, $\mathrm{D}-$ drought stress, $\mathrm{D}+\mathrm{M}-$ drought stress + melatonin. 


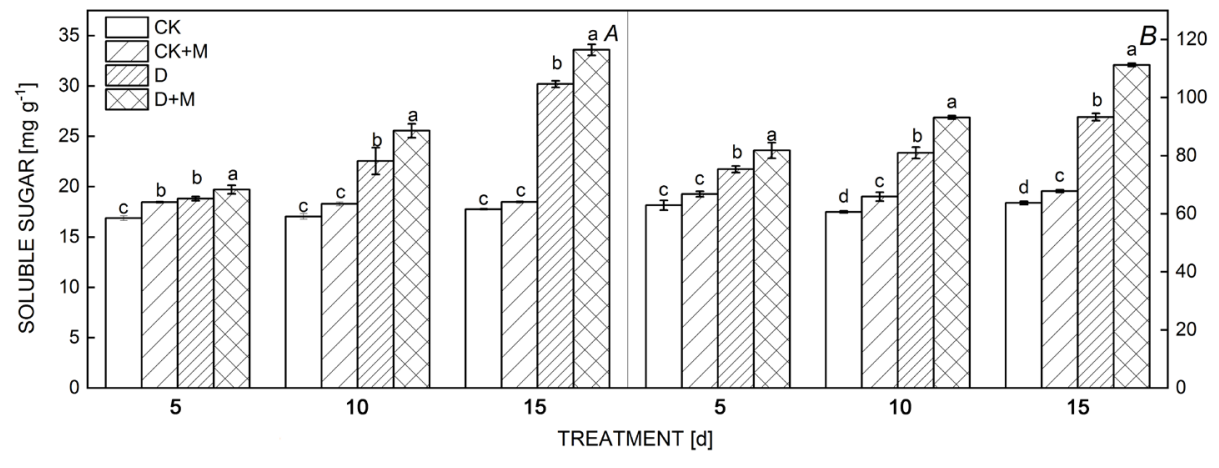

Fig. 3. Effect of melatonin on soluble sugar $(A)$ and soluble - protein $(B)$ concentration in soybean leaves under well$z$ watered and drought stress conditions. All data are means \pm SE $(n=4)$. Different letters above horizontal lines indicate significant differences Oे $(P<0.05)$ between treatments. $\mathrm{CK}$ - well-watered conditions, $\mathrm{CK}$ $+\mathrm{M}-$ well-watered condi-tions + melatonin, D - drought stress, D + $\mathrm{M}$ - drought stress + melatonin.

Table 1. Effects of melatonin on proline content in soybean under drought stress. All data are means $\pm \mathrm{SE}(n=4)$. Different letters within the same row represent significant differences $(P<0.05)$. $\mathrm{CK}-$ well-watered conditions, $\mathrm{CK}+\mathrm{M}$ - well-watered conditions + melatonin, $\mathrm{D}$ - drought stress, $\mathrm{D}+\mathrm{M}$ - drought stress + melatonin.

\begin{tabular}{lllll}
\hline Drought stress [d] & \multicolumn{4}{l}{ Proline $\left[\mu \mathrm{g} \mathrm{g}^{-1}(\mathrm{FM})\right]$} \\
& CK & CK + M & D & D $+M$ \\
\hline 5 & $17.42 \pm 0.29^{\mathrm{c}}$ & $17.10 \pm 0.50^{\mathrm{c}}$ & $22.70 \pm 0.72^{\mathrm{b}}$ & $24.96 \pm 1.04^{\mathrm{a}}$ \\
10 & $18.00 \pm 0.46^{\mathrm{d}}$ & $16.23 \pm 0.14^{\mathrm{c}}$ & $40.51 \pm 0.27^{\mathrm{b}}$ & $54.44 \pm 0.40^{\mathrm{a}}$ \\
15 & $17.62 \pm 0.53^{\mathrm{c}}$ & $16.69 \pm 0.79^{\mathrm{c}}$ & $76.48 \pm 0.27^{\mathrm{b}}$ & $83.84 \pm 0.27^{\mathrm{a}}$ \\
\hline
\end{tabular}

$30.3,125.1$, and $334.0 \%$ after 5,10 , and $15 \mathrm{~d}$ of drought stress, respectively, compared with well-watered plants. These results showed that the application of melatonin effectively maintained the higher water potential and cell turgor in drought-stressed soybean seedlings.

Reactive oxygen species: Leaves were soaked in NBT and $\mathrm{DAB}$ solutions to visualize the spots of $\mathrm{H}_{2} \mathrm{O}_{2}$ and $\mathrm{O}_{2}{ }^{--}$concentrations, respectively. Drought-stressed leaves showed a significant increase in deep blue spots of $\mathrm{O}_{2}{ }^{--}$and dark brown patches of $\mathrm{H}_{2} \mathrm{O}_{2}$ (Fig. 4). However, compared with drought-stressed plants, the $\mathrm{O}_{2}{ }^{-}$and $\mathrm{H}_{2} \mathrm{O}_{2}$ spots were somewhat reduced following exogenous melatonin pretreatment, which is indicative of a reduction in oxidative stress. However, the melatonin treatment did not reduce the $\mathrm{H}_{2} \mathrm{O}_{2}$ and $\mathrm{O}_{2}{ }^{-}$spots in well-watered plants.

Our data confirmed that drought stress induced significant accumulation of $\mathrm{H}_{2} \mathrm{O}_{2}, \mathrm{O}_{2}{ }^{--}$, and MDA when compared to the corresponding levels in well-watered plants (Fig. 5, Table 2). Melatonin treatment decreased the contents of $\mathrm{H}_{2} \mathrm{O}_{2}, \mathrm{O}_{2}{ }^{--}$, and MDA under both wellwatered and drought-stressed conditions. Compared with well-watered plants, drought stress induced significant accumulation of $\mathrm{H}_{2} \mathrm{O}_{2}, \mathrm{O}_{2}^{--}$, and MDA. At 5, 10, and $15 \mathrm{~d}$, the $\mathrm{H}_{2} \mathrm{O}_{2}$ concentration increased by $27.6,48.6$, and $81.9 \%, \mathrm{O}_{2}{ }^{-}$content was elevated by $34.8,62.8$, and $98.4 \%$, and MDA concentration increased by $37.4,72.3$, and 96.0\%, respectively. Exogenous application of melatonin significantly reduced $\mathrm{H}_{2} \mathrm{O}_{2}, \mathrm{O}_{2}{ }^{--}$, and MDA concentrations in drought-stressed soybean leaves. In short, melatonin treatment of water-deficient plants alleviated the toxic effects on cellular metabolism.

Antioxidant enzymes: SOD, POD, and CAT activities were analyzed in the soybean plants. As shown in Table 3, these enzymes were not altered by melatonin pretreatment in well-watered plants. Exposure to drought stress increased the activity of SOD, POD, and CAT, and melatonin pretreatment markedly improved the activities of these enzymes. After 5, 10, and $15 \mathrm{~d}$ of drought stress, SOD activity increased by $26.2,49.4$, and $63.1 \%$; POD activity
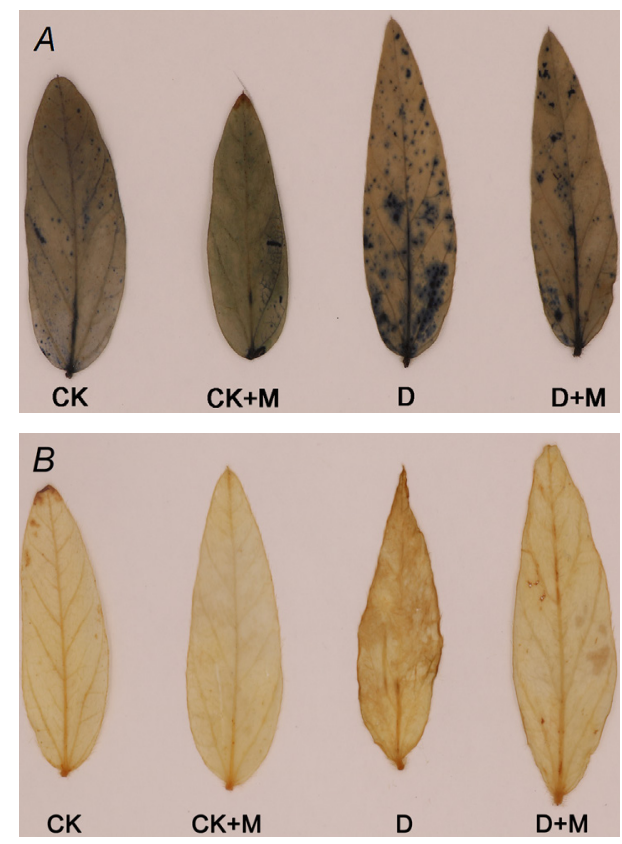

Fig. 4. Histochemical localization of superoxide anion $\left(\mathrm{O}_{2}{ }^{--}\right)$ (upper panel) and hydrogen peroxide $\left(\mathrm{H}_{2} \mathrm{O}_{2}\right)$ (lower panel) in soybean leaves under well-watered and drought stress conditions. CK - well-watered conditions, CK $+\mathrm{M}-$ well-watered conditions + melatonin, $\mathrm{D}-$ drought stress, $\mathrm{D}+\mathrm{M}-$ drought stress + melatonin. 


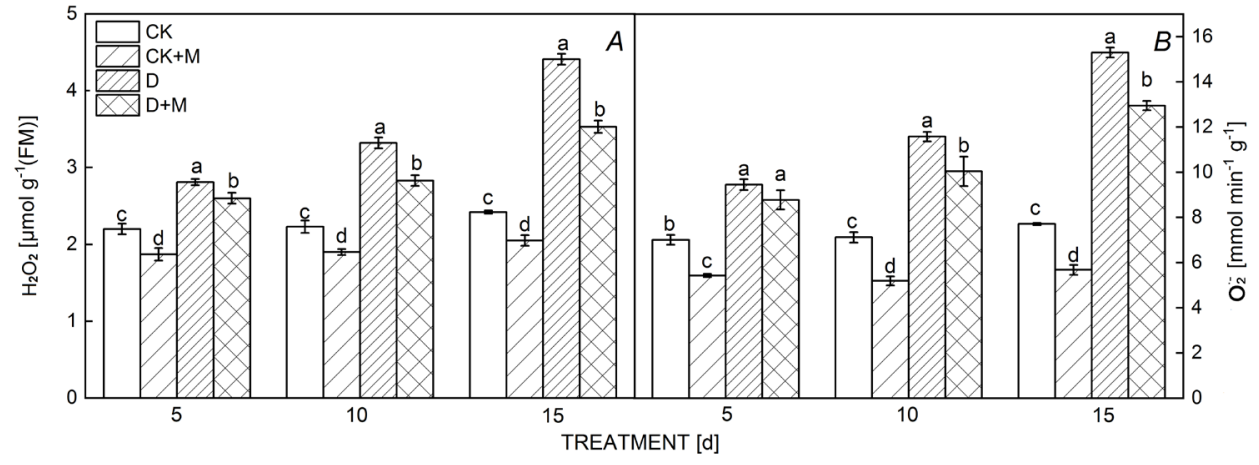

Fig. 5. Effect of melatonin on hydrogen peroxide $\left(\mathrm{H}_{2} \mathrm{O}_{2}\right)(A)$ and superoxide anion $\left(\mathrm{O}_{2}^{-}\right)(B)$ in soybean leaves under wellwatered and drought stress conditions. All data are means \pm SE $(n=4)$. Different letters above horizontal lines indicate significant differences $(P<0.05)$ between treatments. CK - wellwatered conditions, $\mathrm{CK}+\mathrm{M}-$ well-watered conditions + melatonin, $\mathrm{D}-$ drought stress, $\mathrm{D}+\mathrm{M}-$ drought stress + melatonin.

Table 2. Effects of melatonin on malondialdehyde concentration in soybean leaves exposed to drought stress. All data are means $\pm \mathrm{SE}$ $(n=4)$. Different letters within the same row represent significant differences $(P<0.05)$. CK - well-watered conditions, $\mathrm{CK}+\mathrm{M}-$ wellwatered conditions + melatonin, $\mathrm{D}-$ drought stress, $\mathrm{D}+\mathrm{M}-$ drought stress + melatonin.

\begin{tabular}{lllll}
\hline Drought stress [d] & \multicolumn{4}{l}{ Malondialdehyde $\left[\mathrm{nmol} \mathrm{g}^{-1}(\mathrm{FM})\right]$} \\
& CK & CK + M & D & D + M \\
\hline 5 & $0.44 \pm 0.03^{\mathrm{b}}$ & $0.38 \pm 0.01^{\mathrm{b}}$ & $0.60 \pm 0.02^{\mathrm{a}}$ & $0.57 \pm 0.02^{\mathrm{a}}$ \\
10 & $0.37 \pm 0.01^{\mathrm{c}}$ & $0.32 \pm 0.01^{\mathrm{c}}$ & $0.64 \pm 0.02^{\mathrm{a}}$ & $0.55 \pm 0.03^{\mathrm{b}}$ \\
15 & $0.40 \pm 0.02^{\mathrm{c}}$ & $0.36 \pm 0.03^{\mathrm{c}}$ & $0.79 \pm 0.02^{\mathrm{a}}$ & $0.67 \pm 0.04^{\mathrm{b}}$ \\
\hline
\end{tabular}

Table 3. Effects of melatonin on catalase (CAT), superoxide dismutase (SOD), and peroxidase (POD) activity in soybean leaves exposed to drought stress. All data are means $\pm \mathrm{SE}(n=4)$. Different letters within the same row represent significant differences $(P<0.05)$. $\mathrm{CK}$ - well-watered conditions, $\mathrm{CK}+\mathrm{M}$ - well-watered conditions + melatonin, $\mathrm{D}$ - drought stress, $\mathrm{D}+\mathrm{M}-$ drought stress + melatonin.

\begin{tabular}{|c|c|c|c|c|c|}
\hline 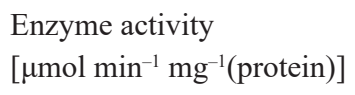 & Drought stress [d] & CK & $\mathrm{CK}+\mathrm{M}$ & $\mathrm{D}$ & $\mathrm{D}+\mathrm{M}$ \\
\hline \multirow[t]{3}{*}{ CAT } & 5 & $29.84 \pm 0.22^{\mathrm{c}}$ & $30.28 \pm 0.97^{c}$ & $50.00 \pm 0.73^{b}$ & $71.44 \pm 1.52^{\mathrm{a}}$ \\
\hline & 10 & $28.84 \pm 0.97^{\mathrm{c}}$ & $30.56 \pm 0.61^{\mathrm{c}}$ & $78.38 \pm 1.59^{\mathrm{b}}$ & $121.44 \pm 0.74^{\mathrm{a}}$ \\
\hline & 15 & $27.52 \pm 1.71^{\mathrm{c}}$ & $28.56 \pm 0.48^{c}$ & $100.23 \pm 2.86^{\mathrm{b}}$ & $127.58 \pm 1.07^{\mathrm{a}}$ \\
\hline \multirow[t]{3}{*}{ SOD } & 5 & $83.61 \pm 3.21^{\mathrm{c}}$ & $84.54 \pm 4.31^{\mathrm{c}}$ & $105.50 \pm 2.87^{b}$ & $127.16 \pm 1.98^{\mathrm{a}}$ \\
\hline & 10 & $81.03 \pm 3.87^{\mathrm{c}}$ & $81.81 \pm 4.06^{\mathrm{c}}$ & $121.07 \pm 5.26^{\mathrm{b}}$ & $143.94 \pm 2.76^{\mathrm{a}}$ \\
\hline & 15 & $82.65 \pm 3.61^{\mathrm{c}}$ & $82.68 \pm 3.06^{c}$ & $134.83 \pm 4.29^{\mathrm{b}}$ & $152.00 \pm 6.83^{\mathrm{a}}$ \\
\hline \multirow[t]{3}{*}{ POD } & 5 & $119.33 \pm 8.66^{c}$ & $133.33 \pm 9.54^{\mathrm{c}}$ & $221.17 \pm 10.21^{\mathrm{b}}$ & $251.33 \pm 9.05^{\mathrm{a}}$ \\
\hline & 10 & $104.33 \pm 8.02^{\mathrm{c}}$ & $112.63 \pm 6.95^{\mathrm{c}}$ & $236.67 \pm 10.31^{b}$ & $262.50 \pm 10.71^{\mathrm{a}}$ \\
\hline & 15 & $147.67 \pm 7.53^{\mathrm{c}}$ & $165.50 \pm 5.80^{c}$ & $392.33 \pm 12.40^{\mathrm{b}}$ & $452.65 \pm 15.81^{\mathrm{a}}$ \\
\hline
\end{tabular}

increased by $85.3,126.8$, and $165.7 \%$; and CAT activity increased by $139.4,321.7$, and $363.5 \%$, respectively, as compared with the activities in well-watered plants.

\section{Discussion}

$\mathrm{Chl}$, the major molecule responsible for photosynthesis, is fragile and easily damaged by ROS, which are generated by environmental stress (Tan et al. 2012). Because of the critical function of $\mathrm{Chl}$, it must be preserved for the survival, growth, and production of plants. Melatonin, as an antioxidant, can prevent the degradation of Chl. Wang et al. (2013) uncovered that melatonin could preserve the integrity of $\mathrm{Chl}$ and increase the photosynthetic efficiency of Chl under both normal conditions and drought stress. The present work indicated that drought significantly decreased the concentration of $\mathrm{Chl}$ and Car, whereas melatonin pretreatment ameliorated this decrease (Fig. 1).

Photosynthesis is a key process in the primary metabolism of plants, and it plays an important role in plant performance under drought stress. Jia et al. (2008) and $\mathrm{Hu}$ et al. (2013) considered that drought stress inhibits photosynthesis through nonstomatal limitation. However, Yin et al. (2005) proposed that drought-mediated inhibition of photosynthesis may be due to stomatal closure. In the present study, we showed that $P_{\mathrm{N}}$ and $g_{\mathrm{s}}$ significantly decreased under drought stress (Fig. 2). After drought stress for 5 and $10 \mathrm{~d}$, the reduced values of $P_{\mathrm{N}}$ were accompanied by a significant decrease in $g_{\mathrm{s}}$ and $C_{\mathrm{i}}$, which indicated that the drought stress-induced $P_{\mathrm{N}}$ decrease was mainly due to the stomatal limitation. However, under the drought stress for $15 \mathrm{~d}$, the reduced values of 
$P_{\mathrm{N}}$ were accompanied by a significant decrease in $g_{\mathrm{s}}$ and an increase in $C_{\mathrm{i}}$, which indicated that the drought stressinduced decline in $P_{\mathrm{N}}$ was mainly due to the nonstomatal limitation. This difference may be due to the destruction of the chloroplast structure in soybean leaves under drought stress, resulting in damage to the photosynthetic organs, decreasing photosynthetic activity and increasing the concentration of $\mathrm{CO}_{2}$. The present results were consistent with the findings in other studies (Yin et al. 2005, Jia et al. 2008, Hu et al. 2013). In our study, melatonin treatment significantly increased $P_{\mathrm{N}}$ and $E$ in soybean leaves when compared to the corresponding levels in drought-stressed leaves.

Soluble sugar, proline, and soluble protein, the most common compatible osmolytes, are actively accumulated to maintain a higher water potential and cell turgor under drought stress, which is the first line of defense against drought (Du et al. 2004, Kaczmarek et al. 2017). Osmolytes are synthesized in response to drought stress and do not interfere with the normal cellular biochemical reactions (Du et al. 2004). The present study showed that the concentrations of various osmolytes, such as soluble sugar, proline, and soluble protein, increased in droughtstressed plants (Fig. 3, Table 1). Compared to droughtstressed plants without melatonin, melatonin-pretreated plants showed significantly higher concentrations of osmolytes.

Earlier studies frequently reported that ROS actively accumulated in drought-stressed plants and damaged cell function (Basu et al. 2010, Deng et al. 2012, Wang et al. 2013). As an antioxidant, melatonin can directly interact with ROS and modulate the activity of antioxidant enzymes in response to excessive ROS (Shi et al. 2015). Wang et al. (2013) considered that melatonin directly scavenges ROS, and in particular, it controls the burst of $\mathrm{H}_{2} \mathrm{O}_{2}$, decreases the contents of MDA, and increases the activity of CAT and POD. Cui et al. (2017) reported that when wheat seedlings were exposed to a water deficit, the exogenous application of melatonin significantly reduced the concentrations of $\mathrm{H}_{2} \mathrm{O}_{2}, \mathrm{O}_{2}{ }^{-}$, and MDA, which was attributed to the increased antioxidant enzyme activity. In this present study, the $\mathrm{H}_{2} \mathrm{O}_{2}$ and $\mathrm{O}_{2}{ }^{-}$localized in the leaf tissue of the soybean plants were visualized by histochemical staining, and drought stress induced excessive accumulation of $\mathrm{H}_{2} \mathrm{O}_{2}$ and $\mathrm{O}_{2}{ }^{-}$ (Fig. 4). $\mathrm{H}_{2} \mathrm{O}_{2}, \mathrm{O}_{2}{ }^{-}$, and MDA, the indicators of oxidative stress, were actively accumulated in the drought-stressed leaves (Fig. 5, Table 2). However, the application of exogenous melatonin reduced the $\mathrm{H}_{2} \mathrm{O}_{2}$ and $\mathrm{O}_{2}{ }^{-}$spots in drought-stressed plants and the concentrations of $\mathrm{H}_{2} \mathrm{O}_{2}$, $\mathrm{O}_{2}{ }^{-}$, and MDA declined, which is indicative of a reduction in oxidative stress. These results were in agreement with several previous reports (Basu et al. 2010, Deng et al. 2012, Wang et al. 2013, Cui et al. 2017).

POD and CAT can effectively scavenge $\mathrm{H}_{2} \mathrm{O}_{2}$ (Wang et al. 2013). The decrease in the concentration of ROS was initially attributed to the antioxidant capacity of melatonin, as evidenced by the improved activity of antioxidant enzymes. This study showed that drought stress treatment increased the activities of SOD, POD, and CAT in the soybean leaves (Table 3). Exogenous melatonin induced upregulation of these enzymes compared to those observed under drought stress (Table 3). Thus, the protective effect of melatonin against drought stress could be ascribed to its antioxidant capacity and free radical scavenging.

Conclusion: The results of the present study demonstrated that drought stress decreased the concentrations of photosynthetic pigments and $P_{\mathrm{N}}$, and increased $\mathrm{O}_{2}{ }^{-}, \mathrm{H}_{2} \mathrm{O}_{2}$, and MDA concentrations. The results also showed that, compared to drought-stressed plants, foliar application of melatonin $\left(100 \mathrm{mg} \mathrm{L}^{-1}\right)$ at the seedling stage improved photosynthesis and maintained the balance in ROS metabolism (ROS production and removal). This suggests that exogenous melatonin is an effective protectant that improves drought tolerance in soybean seedlings by enhancing antioxidant enzymes and reducing oxidative damages.

\section{References}

Alonso R., Elvira S., Castillo F.J., Gimeno B.S.: Interactive effects of ozone and drought stress on pigments and activities of antioxidative enzymes in Pinus halepensis. - Plant Cell Environ. 24: 905-916, 2001.

Arnon D.T.: Copper enzymes in isolated chloroplasts. Polyphenol oxidase in Beta vulgaris. - Plant Physiol. 24: 1-15, 1949.

Basu S., Roychoudhury A., Saha P.P., Sengupta D.N.: Differential antioxidative responses of indica rice cultivars to drought stress. - Plant Growth Regul. 60: 51-59, 2010.

Bates L.S., Waldren R.P., Teare I.D.: Rapid determination of free proline for water-stress studies. - Plant Soil 39: 205-207, 1973.

Chen F., Wang F., Wu F. et al:: Modulation of exogenous glutathione in antioxidant defense system against $\mathrm{Cd}$ stress in the two barley genotypes differing in Cd tolerance. - Plant Physiol. Bioch. 48: 663-672, 2010.

Cui G., Zhao X., Liu S. et al.: Beneficial effects of melatonin in overcoming drought stress in wheat seedlings. - Plant Physiol. Bioch. 118: 138-149, 2017.

Deng B., Du W., Liu C. et al.: Antioxidant response to drought, cold and nutrient stress in two ploidy levels of tobacco plants: low resource requirement confers polytolerance in polyploids? - Plant Growth Regul. 66: 37-47, 2012.

Du J.Y, Chen X.Y., Li W. et al.: Osmoregulation mechanism of drought stress and genetic engineering strategies for improving drought resistance in plants. - For. Stud. China 6: 56-62, 2004.

Dubbels R., Reiter R.J., Klenke E. et al.: Melatonin in edible plants identified by radioimmunoassay and by high performance liquid chromatography-mass spectrometry. - J. Pineal Res. 18: 28-31, 1995.

Fu J., Huang B.: Involvement of antioxidants and lipid peroxidation in the adaptation of two cool-season grasses to localized drought stress. - Environ. Exp. Bot. 45: 105-114, 2001.

Guidi L., Tonini M., Soldatini G.F.: Effects of high light and ozone fumigation on photosynthesis in Phaseolus vulgaris. Plant Physiol. Bioch. 38: 717-725, 2000.

Harrison M.T., Tardieu F., Dong Z. et al.: Characterizing drought stress and trait influence on maize yield under current and future conditions. - Glob. Change Biol. 20: 867-878, 2014.

Hattori A., Migitaka H., Iigo M. et al.: Identification of melatonin in plants and its effects on plasma melatonin levels and binding to melatonin receptors in vertebrates. - Biochem. Mol. Biol. Int. 35: 627-634, 1995. 
Hendrix D.L.: Rapid extraction and analysis of nonstructural carbohydrates in plant tissues. - Crop Sci. 33: 1306-1311, 1993.

Hu W.H., Yan X.H., Xiao Y.A. et al.: 24-Epibrassinosteroid alleviate drought-induced inhibition of photosynthesis in Capsicum annuum. - Sci. Hortic.-Amsterdam 150: 232-237, 2013.

Jia H., Oguchi R., Hope A. et al.: Differential effects of severe water stress on linear and cyclic electron fluxes through Photosystem I in spinach leaf discs in $\mathrm{CO}_{2}$-enriched air. Planta 228: 803-812, 2008.

Kaczmarek M., Fedorowicz-Strońska O., Głowacka K. et al.: $\mathrm{CaCl}_{2}$ treatment improves drought stress tolerance in barley (Hordeum vulgare L.). - Acta Physiol. Plant. 39: 41, 2017.

Li C., Wang P., Wei Z. et al.: The mitigation effects of exogenous melatonin on salinity-induced stress in Malus hupehensis. J. Pineal Res. 53: 298-306, 2012.

Maehly A.C.: The assay of catalases and peroxidases. In: Glick D. (ed.): Methods of Biochemical Analysis. Vol. 1. Pp. 357-424. John Wiley \& Sons, Inc., 1954.

Patterson B.D., MacRae E.A., Ferguson I.B.: Estimation of hydrogen peroxide in plant extracts using titanium(IV). Anal. Biochem. 139: 487-492, 1984.

Posmyk M.M., Kuran H., Marciniak K., Janas K.M.: Presowing seed treatment with melatonin protects red cabbage seedlings against toxic copper ion concentrations. - J. Pineal Res. 45: 24-31, 2008

Shi H., Jiang C., Ye T. et al.: Comparative physiological, metabolomic, and transcriptomic analyses reveal mechanisms of improved abiotic stress resistance in bermudagrass [Cynodon dactylon (L). Pers.] by exogenous melatonin. -
J. Exp. Bot. 66: 681-694, 2015.

Smith P.K., Krohn R.I., Hermanson G.T. et al.: Measurement of protein using bicinchoninic acid. - Anal. Biochem. 150: 76-85, 1985.

Tan D.X., Hardeland R., Manchester L.C. et al.: Functional roles of melatonin in plants, and perspectives in nutritional and agricultural science. - J. Exp. Bot. 63: 577-597, 2012.

Wang A.G., Luo G.H.: The quantitative relationship between superoxide radical reaction and hydroxylamine in plants. Plant Physiol. Commun. 26: 55-57, 1990. [In Chinese]

Wang P., Sun X., Li C. et al.: Long-term exogenous application of melatonin delays drought-induced leaf senescence in apple. - J. Pineal Res. 54: 292-302, 2013.

Wei W., Li Q.T., Chu Y.N. et al.: Melatonin enhances plant growth and abiotic stress tolerance in soybean plants. J. Exp. Bot. 66: 695-707, 2015.

Yin C., Peng Y., Zang R. et al.: Adaptive responses of Populus kangdingensis to drought stress. - Physiol. Plantarum 123: 445-451, 2005.

Zhang L.J., Jia J.F., Xu Y. et al.: Production of transgenic Nicotiana sylvestris plants expressing melatonin synthetase genes and their effect on UV-B-induced DNA damage. In Vitro Cell. Dev.-Pl. 48: 275-282, 2012.

Zhang N., Zhang H.J., Zhao B. et al.: The RNA-seq approach to discriminate gene expression profiles in response to melatonin on cucumber lateral root formation. - J. Pineal Res. 56: 39-50, 2014.

Zhang N., Zhao B., Zhang H.J. et al.: Melatonin promotes waterstress tolerance, lateral root formation, and seed germination in cucumber (Cucumis sativus L.). - J. Pineal Res. 54: 15-23, 2012.

(C) The authors. This is an open access article distributed under the terms of the Creative Commons BY-NC-ND Licence. 